\title{
Involvement of Nitric Oxide in a Rat Model of Carrageenin-Induced Pleurisy
}

\author{
Masahiro Iwata, ${ }^{1,2}$ Shigeyuki Suzuki, ${ }^{2}$ Yuji Asai,, ${ }^{1}$ Takayuki Inoue, ${ }^{3}$ and Kenji Takagi ${ }^{4}$ \\ ${ }^{1}$ Department of Rehabilitation, Faculty of Health Sciences, Nihon Fukushi University, 26-2 Higashihaemi-cho, \\ Handa 475-0012, Japan \\ ${ }^{2}$ Department of Physical Therapy, Nagoya University School of Health Sciences, 1-1-20 Daikominami, Higashi-ku, \\ Nagoya 461-8673, Japan \\ ${ }^{3}$ Department of Rehabilitation, Nagoya University Hospital, 1-1-20 Daikominami, Higashi-ku, Nagoya 461-8673, Japan \\ ${ }^{4}$ Program in Radiological and Medical Laboratory Sciences, Nagoya University Graduate School of Medicine, 1-1-20 Daikominami, \\ Higashi-ku, Nagoya 461-8673, Japan
}

Correspondence should be addressed to Shigeyuki Suzuki, suzuki@met.nagoya-u.ac.jp

Received 25 November 2009; Accepted 24 March 2010

Academic Editor: Jan van Amsterdam

Copyright ( $\odot 2010$ Masahiro Iwata et al. This is an open access article distributed under the Creative Commons Attribution License, which permits unrestricted use, distribution, and reproduction in any medium, provided the original work is properly cited.

Some evidence indicates that nitric oxide (NO) contributes to inflammation, while other evidence supports the opposite conclusion. To clarify the role of NO in inflammation, we studied carrageenin-induced pleurisy in rats treated with an NO donor (NOC-18), a substrate for NO formation (L-arginine), and/or an NO synthase inhibitor (S-(2-aminoethyl) isothiourea or $\mathrm{N}^{\mathrm{G}}$-nitro-L-arginine). We assessed inflammatory cell migration, nitrite/nitrate values, lipid peroxidation and pro-inflammatory mediators. NOC-18 and L-arginine reduced the migration of inflammatory cells and edema, lowered oxidative stress, and normalized antioxidant enzyme activities. NO synthase inhibitors increased the exudate formation and inflammatory cell number, contributed to oxidative stress, induced an oxidant/antioxidant imbalance by maintaining high $\mathrm{O}_{2}{ }^{-}$, and enhanced the production of pro-inflammatory mediators. L-arginine and NOC-18 reversed the proinflammatory effects of NO synthase inhibitors, perhaps by reducing the expression of adhesion molecules on endothelial cells. Thus, our results indicate that NO is involved in bluntingnot enhancing — the inflammatory response.

\section{Introduction}

Inflammation is a protective process essential for the preservation of the integrity of organisms in the event of physical, chemical, or infectious damage. Acute inflammation, which is characterized by pain, heat, redness, and swelling, involves a complex series of events including vasodilatation, increased permeability, fluid exudation, and migration of leukocytes to the site of inflammation [1].

At the site of an inflammatory reaction, the injured vascular endothelial cells and the emigrated leukocytes synthesize and release an intricate cascade of inflammatory mediators including nitric oxide (NO). NO is an oxidant synthesized de novo in cells from L-arginine by isoforms of NO synthase (NOS), including neuronal NOS (nNOS or NOS1), inducible NOS (iNOS or NOS2), and endothelial NOS (eNOS or NOS3) [2]. Generally, nNOS and eNOS are constitutively expressed, whereas iNOS is induced in response to inflammatory-like stimuli and is capable of sustained production of high levels of NO that predominate during inflammation $[2,3]$. Although the cytostatic/cytocidal activity of NO is part of the host defense mechanism, the excessive or inappropriate production of $\mathrm{NO}$ can damage tissue, possibly through the formation of peroxynitrite $\left(\mathrm{ONOO}^{-}\right)$, a potent oxidizing and nitrating agent, via the coupling of $\mathrm{NO}$ with superoxide anion $\left(\mathrm{O}_{2}{ }^{-}\right)$ $[4,5] . \mathrm{N}^{\mathrm{G}}$-monomethyl-L-arginine (L-NMMA), which is an arginine analogue that competitively inhibits the constitutive isoforms of NOS (cNOS: eNOS and nNOS) and iNOS, significantly reduced NO levels and concomitantly reduced synovial inflammation and tissue damage in streptococcal cell wall (SCW)-induced arthritis [6] and adjuvant arthritis 
[7] in rodents. Furthermore, NO-mediated production of $\mathrm{ONOO}^{-}$in humans occurs in oxidative processes associated with atherogenesis [8] and acute lung injury [9]. Although this evidence suggests that NO plays a pro-inflammatory role, some reports contradict this finding. For example, the stimulation of endogenous NO production or exogenous administration of NO-donating compounds often blunts the ultimate expression of tissue injury at both the molecular and functional levels in cerebrovascular [10], hepatic [11], splanchnic [12], renal [13], pulmonary [14], myocardial [15], inflammatory, and ischemia/reperfusion injury models. Interestingly, this $\mathrm{NO}$-dependent protective effect occurs in processes with increased rates of $\mathrm{O}_{2}{ }^{-}$production and for which oxidant injury plays an etiological role [10, 11].

Carrageenin $(\mathrm{Cg})$-induced pleurisy in rats is a wellcharacterized experimental model of acute inflammation that permits the quantification and correlation of both exudate and cellular migration with changes in other inflammatory parameters [16]. In this model, polymorphonuclear leukocytes are the predominant cell type for 12 hours after $\mathrm{Cg}$ injection; then, they are replaced by migrating mononuclear cells that differentiate into macrophages and dominate the reaction until resolution at 48 hours $[17,18]$. Thus, this model is suitable for studying the relationships among migrating cells, exudates, NO, pro-inflammatory cytokines, and chemokines.

The maintenance of leukocyte recruitment during inflammation requires intercellular communication between infiltrating leukocytes and the endothelium. These events are mediated by early response cytokines such as interleukin- $1 \beta$ (IL-1 $\beta$ ) and tumor necrosis factor- $\alpha$ (TNF- $\alpha)$, cell-surface adhesion molecules, and chemotactic molecules such as chemokines [19].

Chemokines are a family of structurally related glycoproteins with potent leukocyte activation and/or chemotactic activity. Most chemokines are produced in response to inflammatory stimuli, such as the early-response cytokines, TNF- $\alpha$, IL- $1 \beta$, C5a, leukotriene B4, and interferons [20]. Monocyte chemoattractant protein-1 (MCP-1) is a chemokine that attracts monocytes and neutrophils both in vitro and in vivo, and it appears to be a key part of leukocyte emigration by promoting the transition from leukocyte rolling to adhesion on the endothelial surface [21].

In the present study, we analyzed the involvement of $\mathrm{NO}$ on inflammatory cell migration, nitrite/nitrate values, lipid peroxidation, and pro-inflammatory mediators (TNF$\alpha$, IL- $1 \beta, \mathrm{MCP}-1$ and $\mathrm{O}_{2}{ }^{-}$) in Cg-induced pleurisy in rats by administering NOC-18 (a donor of NO) [22], L-arginine (a substrate for NO formation), S-(2-aminoethyl) isothiourea (AE-ITU: an inhibitor of iNOS) [23], and $\mathrm{N}^{\mathrm{G}}$-nitro-Larginine (L-NNA: an inhibitor of cNOS and iNOS) [24] in combination with $\mathrm{Cg}$ injection.

\section{Materials and Methods}

2.1. Reagents. S-(2-aminoethyl) isothiourea (AE-ITU), $\mathrm{N}_{-}^{\mathrm{G}}$ nitro-L-arginine (L-NNA), and 1-Hydroxy-2-oxo-3,3-bis(2aminoethyl)-1-triazene (NOC-18) were purchased from Dojindo (Kumamoto, Japan). Unless otherwise noted, all other chemicals used were of the purest grade and obtained from Sigma Chemical (St. Louis, MO, USA).

2.2. Animals. Male Wistar rats (Japan SLC, Shizuoka, Japan) weighing 150 to $170 \mathrm{~g}$ were used in this study. Food and water were available ad libitum. The light cycle was automatically controlled (12-hour light, 12-hour dark), and the room temperature was maintained at $23 \pm 1^{\circ} \mathrm{C}$. For 4 days prior to the experiments, animals were housed under these conditions to allow for acclimatization. All experiments were performed according to the Guidelines for Animal Experimentation of Nagoya University.

2.3. Induction of Cg-Induced Pleurisy and Measurement of Inflammatory Parameters. Animals were slightly anesthetized with diethyl ether; subsequently, $0.15 \mathrm{~mL}$ of physiological saline solution or $1 \%(\mathrm{w} / \mathrm{v}) \lambda$-Cg (Sigma Chemical, St. Louis, MO, USA) suspended in physiological saline was injected into the right pleural cavity. After 2, 6, $12,24,36,54$, and 72 hours, animals were sacrificed via exsanguination from the abdominal aorta under deep etheranesthesia. Pleural exudate from each animal was harvested by washing the pleural cavity with $1 \mathrm{~mL}$ of $3.15 \%(\mathrm{w} / \mathrm{v})$ sodium citrate in physiological saline as an anticoagulant. Exudates contaminated with blood were rejected. Exudate volumes were measured, and the volume injected into the pleural cavity $(1 \mathrm{~mL})$ was subtracted from the total volume recovered. Exudate samples were then centrifuged at $800 \times \mathrm{g}$ for 10 minutes, after which cell pellets were resuspended in saline. To estimate the number of cells in each sample, cells were stained with trypan blue and then counted by using an optical microscope with a Burker counting chamber. In some experiments, differential cell counts were determined in smears by May-Grunwald staining.

2.4. Treatments. In the first set of experiments, rats (6 to 8 rats per group) received an intrapleural $\mathrm{Cg}$ injection immediately after intrapleural administration of vehicle (saline), $10 \mathrm{mg} / \mathrm{kg}$ of AE-ITU, $1 \mathrm{mg} / \mathrm{kg}$ of L-NNA, $10 \mathrm{mg} / \mathrm{kg}$ of NOC-18, or $30 \mathrm{mg} / \mathrm{kg}$ of L-arginine. The doses of AEITU [25], L-NNA [26], NOC-18 [27], and L-arginine [27] were based on previous reports from the literature with modification of the administration route. Five additional groups of rats ( 5 rats per group) were treated with $10 \mathrm{mg} / \mathrm{kg}$ of AE-ITU, $1 \mathrm{mg} / \mathrm{kg}$ of L-NNA, $10 \mathrm{mg} / \mathrm{kg}$ of NOC-18, or $30 \mathrm{mg} / \mathrm{kg}$ of L-arginine, but they did not receive the $\mathrm{Cg}$ injection. After 6 hours, the rats were sacrificed, and pleural exudates were collected and processed as described above.

In the second set of experiments, rats $(6$ rats per group) treated with AE-ITU (10 mg/kg) or L-NNA ( $1 \mathrm{mg} / \mathrm{kg})$ immediately before $\mathrm{Cg}$ injection also received intrapleural injections of NOC-18 (10 mg/kg) or L-arginine $(30 \mathrm{mg} / \mathrm{kg})$. NOC-18 and L-arginine treatments were performed simultaneously with NOS inhibitor injection. Animals were sacrificed 6 hours after the induction of pleurisy, and pleural exudates were collected and processed. In each set of experiments, the control group received only vehicle(s) via the appropriate route of administration. 
2.5. Nitrite/Nitrate Assay. The amount of nitrites and nitrates, which are indicators of NO synthesis, in the supernatant of centrifuged exudate was measured with a colorimetric commercial kit (Nitrite/Nitrate Assay Kit-C II; Dojindo), according to the manufacturer's instructions.

2.6. Malondialdehyde Assay. We used the thiobarbituric acid reactive substances (TBARS) method as an index of lipid peroxidation for analyzing malondialdehyde (MDA) products during an acid-heating reaction, as previously described by Draper and coworkers [28]. Briefly, the supernatant of $200 \mu \mathrm{L}$ of centrifuged exudates was mixed with $1 \mathrm{~mL}$ of $10 \%$ trichloroacetic acid and $1 \mathrm{~mL}$ of $0.67 \%$ thiobarbituric acid; the samples were then heated in a boiling water bath for 30 minutes. TBARS levels were determined by absorbance at $532 \mathrm{~nm}$ and expressed as malondialdehyde equivalents.

2.7. Assay for TNF- $\alpha, I L-1 \beta$, and MCP-1. TNF- $\alpha$, IL- $1 \beta$ and MCP-1 were measured in the supernatant of centrifuged exudates by enzyme-immunoassay kits (BioSource International, Camarillo, CA, USA), according to the manufacturer's instructions.

2.8. Total Antioxidant Status Assay. The total antioxidant status (TAOS) is an indication of $\mathrm{O}_{2}{ }^{-}$and other oxidant species. The TAOS of the supernatant of centrifuged exudate was determined as previously described [29]. Briefly, the reaction mixture consisted of (final concentrations):

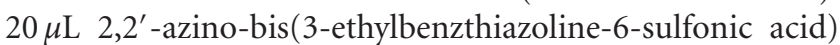
(ABTS; $2 \mathrm{mM}), 10 \mu \mathrm{L}$ horseradish peroxidase $(30 \mathrm{mU} / \mathrm{mL})$, $20 \mu \mathrm{L} \mathrm{H}_{2} \mathrm{O}_{2}(0.1 \mathrm{mM}), 40 \mu \mathrm{L}$ phosphate-buffered saline (PBS; in mM: $137 \mathrm{NaCl}, 8.10 \mathrm{Na}_{2} \mathrm{HPO}_{4}, 2.68 \mathrm{KCl}, 1.47 \mathrm{KH}_{2} \mathrm{PO}_{4}$, $\mathrm{pH} 7.40$ ), and $10 \mu \mathrm{L}$ of sample in a total volume of $100 \mu \mathrm{L}$ per well of 96 -well plates. The reaction, which was initiated upon the addition of $\mathrm{H}_{2} \mathrm{O}_{2}$, was conducted at $37^{\circ} \mathrm{C}$. The increase in absorbance at $405 \mathrm{~nm}$, a reflection of 2,2'-azino-bis(3ethylbenzthiazoline-6-sulfonic acid) radical cation $\left(\mathrm{ABTS}^{+}\right)$ accumulation, was measured by using a microplate reader (Molecular Devices, Crawley, UK).

2.9. Statistical Analysis. All data are expressed as the mean \pm standard error of the mean (S.E.M.). The statistical analysis was conducted by using ANOVA followed by the Bonferroni $t$-test. Differences between groups were considered statistically significant when $P<.05$.

\section{Results}

3.1. Time Course of Exudate Formation and Cellular Infiltration. The pleural cavity of control rats that did not receive $\mathrm{Cg}$ or drugs contained no exudates and $2.9 \pm 0.5 \times 10^{6}$ cells per rat $(n=5)$, and these cells were predominantly mononuclear (>95\%). Injection of $0.15 \mathrm{~mL}$ of $1 \% \mathrm{Cg}$ into the pleural cavity of rats caused an inflammatory response characterized by exudate formation and cell migration (Figure 1). The exudate volume and the number of leukocytes in the pleural cavity increased with time, reaching a maximum at 24 hours $\left(2.11 \pm 0.08 \mathrm{~mL} / \mathrm{rat}\right.$ and $\left.108.6 \pm 7.5 \times 10^{6} \mathrm{cells} / \mathrm{rat}, n=8\right)$

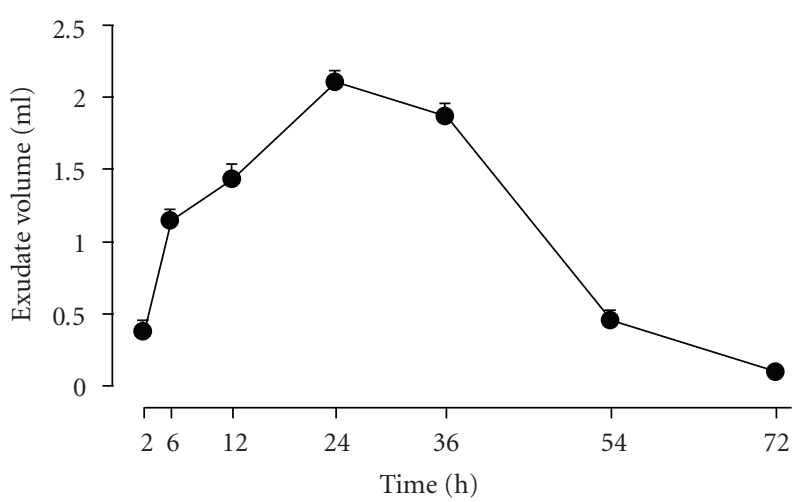

(a)

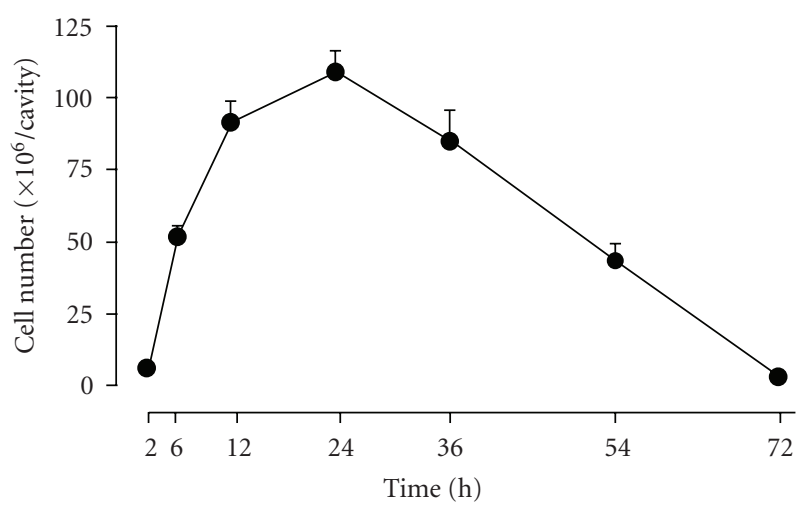

(b)

Figure 1: Time course of rat Cg pleurisy. Exudate volume (a) and leukocyte infiltration (b) were evaluated at different time points after $\mathrm{Cg}$ injection. The values are expressed as mean \pm S.E.M. of 6 to 8 rats.

and decreasing at 54 hours $(0.46 \pm 0.07 \mathrm{~mL} /$ rat and 43.3 $\pm 6.1 \times 10^{6}$ cells/rat, $\left.n=7\right)$. Both levels returned to the background levels by 72 hours. Differential cell counts of leukocytes that migrated into the pleural cavity showed that polymorphonuclear leukocytes dominated the early phase $(2$ hours) of the reaction (89\% polymorphonuclear leukocytes and $11 \%$ mononuclear leukocytes) and were then replaced at 54 hours by mononuclear leukocytes ( $26 \%$ polymorphonuclear leukocytes and $74 \%$ mononuclear leukocytes).

\subsection{Time Course of Nitrite/Nitrate Production in the Exudate} of Cg-Induced Rat Pleurisy. We measured the levels of nitrite/nitrate in the pleural exudate of rats at different time points after the induction of pleurisy. As shown in Figure 2, nitrite/nitrate was detectable in the pleural exudate at 2 hours and peaked at 6 hours after $\mathrm{Cg}$ injection before gradually decreasing.

3.3. Effects of AE-ITU, L-NNA, NOC-18, or L-Arginine on Cg-Induced Rat Pleurisy. To determine the contribution of $\mathrm{NO}$ to the inflammatory response, we measured the effects of AE-ITU (selective iNOS inhibitor), L-NNA (non-selective NOS inhibitor), NOC-18 (a donor of NO), or L-arginine (a substrate for NO formation) administered directly into the 


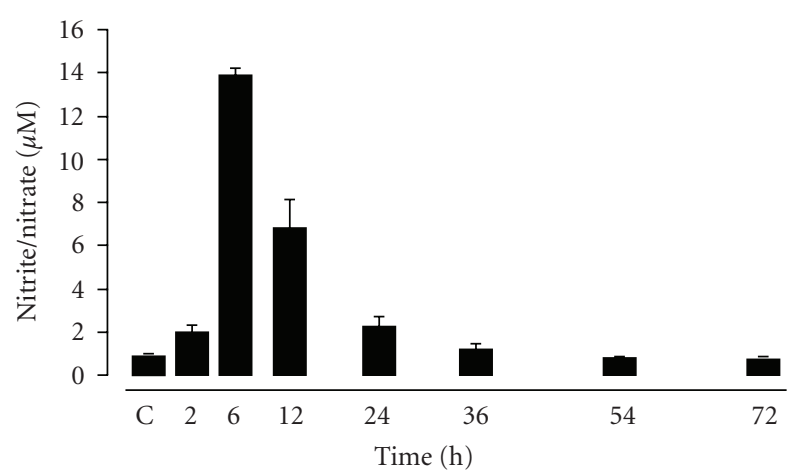

FIgURE 2: Time course of nitrite/nitrate levels. The nitrite/nitrate assay was performed in rat pleural exudates collected from control rats (C) or Cg-treated rats at 2, 6, 12, 24, 36, 54, and 72 hours after pleural injection. The values are expressed as mean \pm S.E.M. of 6 to 8 rats.

pleural cavity immediately before $\mathrm{Cg}$ injection. The exudate formation and inflammatory cell number were significantly increased with the addition of AE-ITU (both $P<.01$ ) (Figures 3(a) and 3(b)) or L-NNA $(P<.05$ and $P<.01$, resp.). Both the $\mathrm{Cg}+\mathrm{AE}-\mathrm{ITU}$ and $\mathrm{Cg}+\mathrm{L}-\mathrm{NNA}$ groups showed a marked reduction in the levels of nitrite/nitrate as compared to the Cg group (both $P<.01$ ) (Figure 3(c)). No statistical differences were observed between the $\mathrm{Cg}+\mathrm{AE}-$ ITU and Cg + L-NNA groups.

In a parallel experiment, the exudate volume and the number of inflammatory cells were significantly reduced by the addition of NOC-18 $(P<.05$ and $P<.01)$ (Figure $4(\mathrm{a})$ ) or L-arg (both $P<.01$ ) (Figure 4(b)). Both the Cg + NOC18 and $\mathrm{Cg}+\mathrm{L}$-arg groups had markedly increased levels of nitrite/nitrate as compared to the Cg group (both $P<.01$ ) (Figure 4(c)).

3.4. Effects of NOC-18, or L-Arginine on the Influence of AE-ITU or L-NNA on Cg-Induced Rat Pleurisy. Next, we determined if the changes in the NO level were responsible for the exacerbation of inflammation at 6 hours by AE-ITU and L-NNA. When NOC-18 was injected in rats simultaneously treated with AE-ITU or L-NNA, the exacerbating influences of these NOS inhibitors were completed reversed (Figure 5). Similar results were obtained with L-arginine (data not shown).

3.5. Effects of AE-ITU, L-NNA, NOC-18 or L-Arginine on Pleural Inflammation in the Absence of $\mathrm{Cg}$. To show that AE-ITU, L-NNA, NOC-18 or L-arginine did not affect inflammation simply as a result of direct irritation, these compounds or vehicle were injected into the pleural cavity in the absence of $\mathrm{Cg}$. None of these compounds caused exudate formation or an increase in the cellular influx (data not shown).

3.6. Effect of AE-ITU, L-NNA, NOC-18, or L-Arginine on Malondialdehyde Content in Pleural Exudates. The MDA levels in the $\mathrm{Cg}(P<.01), \mathrm{Cg}+\mathrm{AE}-\mathrm{ITU}(P<.01)$ and

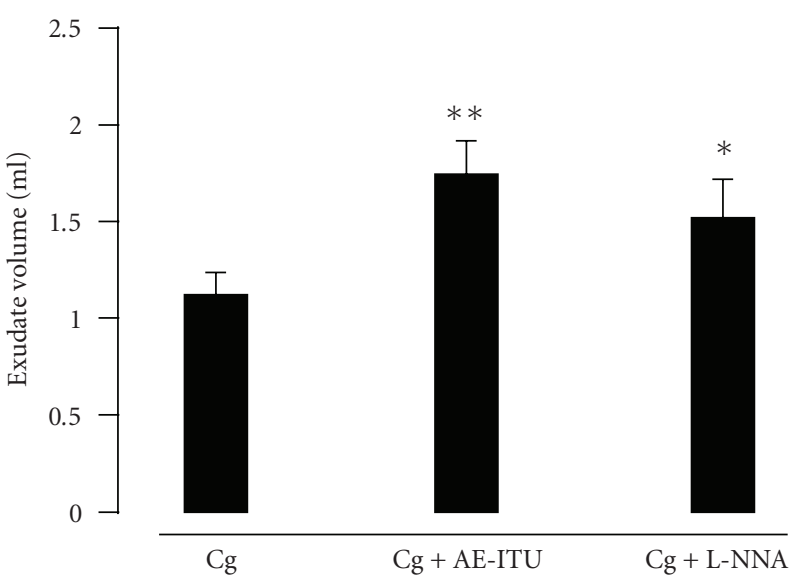

(a)

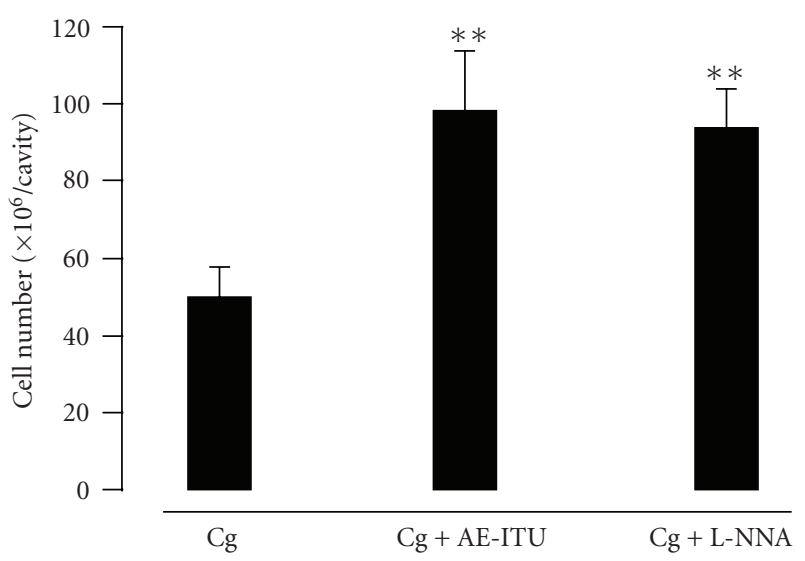

(b)

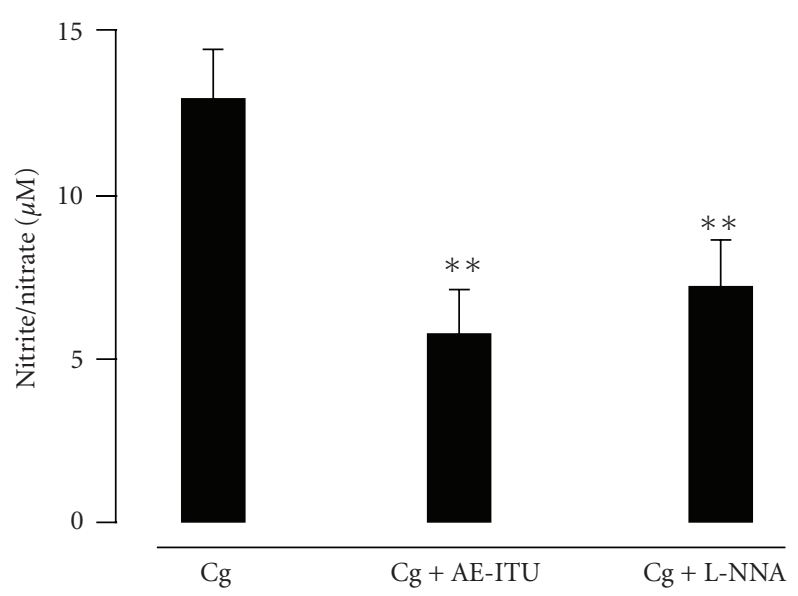

(c)

Figure 3: Effects of AE-ITU and L-NNA on rat Cg pleurisy and nitrite/nitrate levels. AE-ITU or L-NNA was injected into the pleural cavity immediately before $\mathrm{Cg}$ injection. The exudate volume (a), cell number (b), and nitrite/nitrate levels (c) in the pleural exudates were determined 6 hours after $\mathrm{Cg}$ injection. Data are expressed as mean \pm S.E.M. of 6 to 8 rats. ${ }^{*} P<.05,{ }^{* *} P<.01$ as compared to the Cg group. 


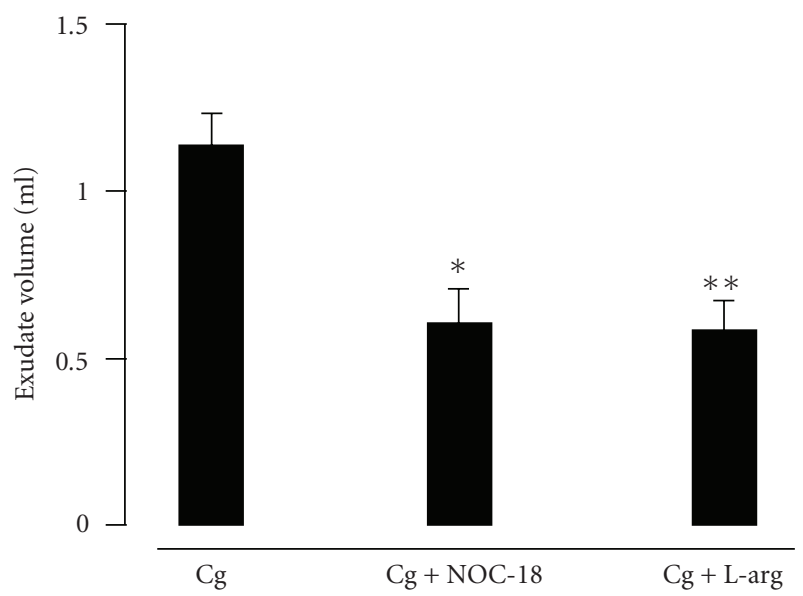

(a)

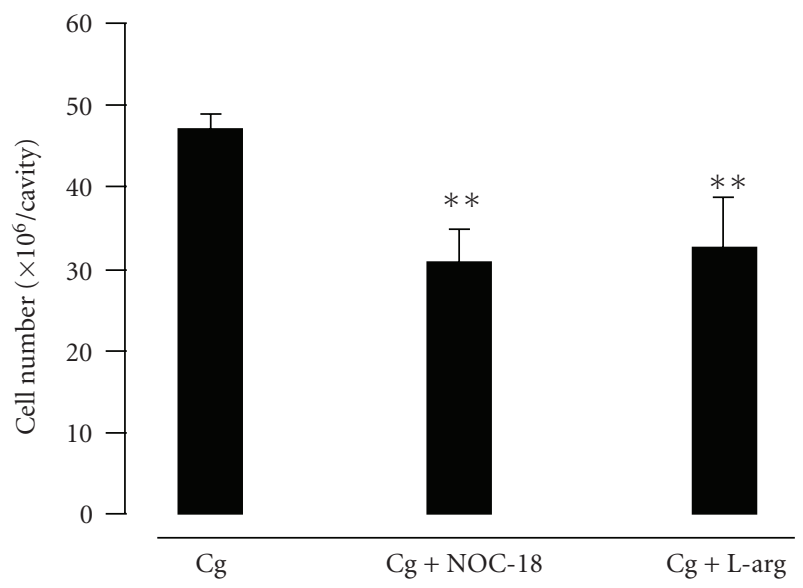

(b)

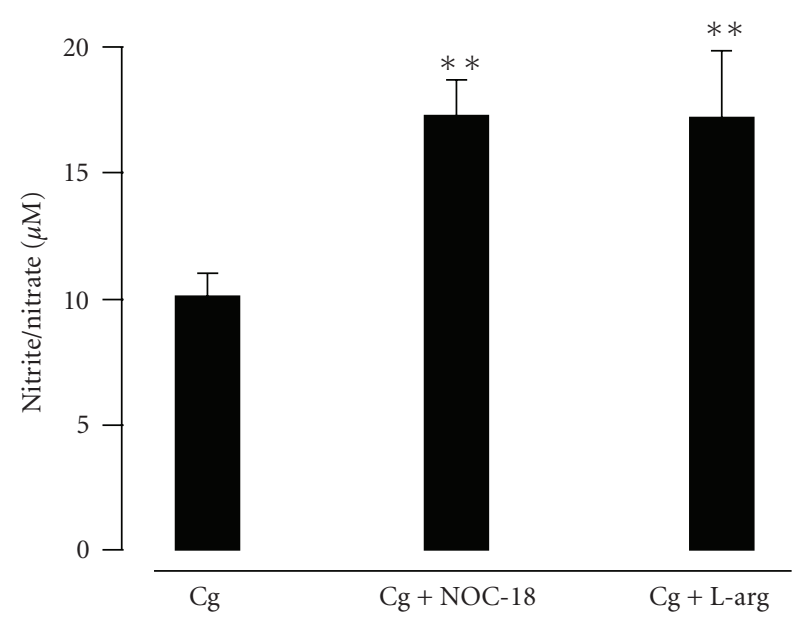

(c)

FIGURE 4: Effects of NOC-18 and L-arginine on rat Cg pleurisy and nitrite/nitrate levels. NOC18 or L-arginine was injected into the pleural cavity immediately before $\mathrm{Cg}$ injection. The exudate volume (a), cell number (b), and nitrite/nitrate levels (c) in the pleural exudates were determined 6 hours after $\mathrm{Cg}$ injection. Data are expressed as mean \pm S.E.M. of 6 to 8 rats. ${ }^{*} P<.05,{ }^{* *} P<.01$ as compared to the $\mathrm{Cg}$ group.

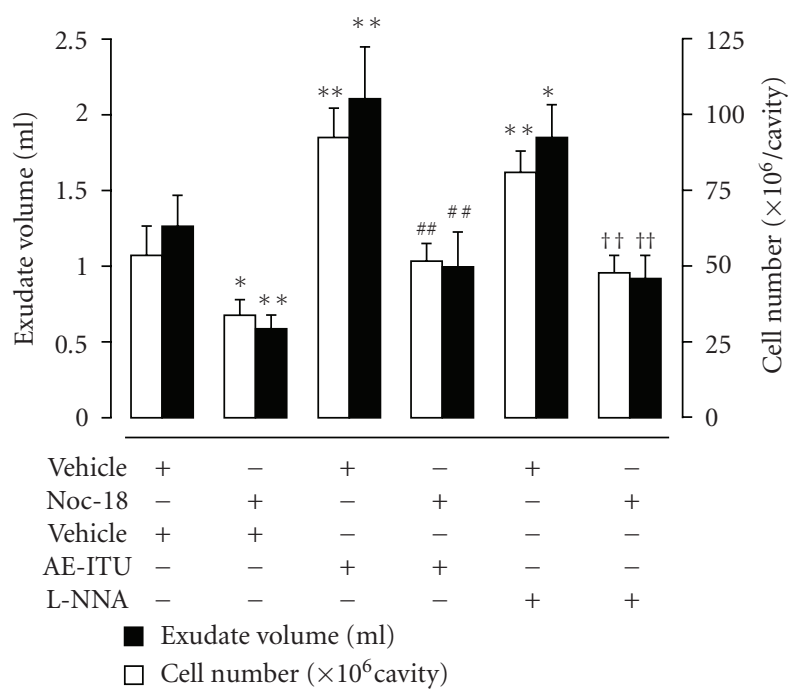

FIgURE 5: Effects of NOC-18 on the influence of AE-ITU and LNNA on exudate volume (empty columns) and cell infiltration (filled columns) 6 hours after $\mathrm{Cg}$ challenge. Each column represents the mean \pm S.E.M. of 6 rats. ${ }^{*} P<.05,{ }^{* *} P<.01$ as compared to the vehicle plus vehicle; ${ }^{\#} P<.01$ as compared to the vehicle plus AE-ITU; ${ }^{\dagger+} P<.01$ as compared to the vehicle plus L-NNA.

$\mathrm{Cg}+\mathrm{L}-\mathrm{NNA}$ groups $(P<.01)$ were significantly increased as compared to the control group (Figure 6). MDA levels in the $\mathrm{Cg}+\mathrm{AE}-\mathrm{ITU}$ and $\mathrm{Cg}+\mathrm{L}-\mathrm{NNA}$ groups were increased as compared to that of the $\mathrm{Cg}$ group (both $P<.01$ ). On the other hand, the Cg + NOC-18 and Cg + L-arg groups had a decreased MDA level as compared to the $\mathrm{Cg}$ group (both $P<.01)$. MDA levels in the Cg + NOC- 18 and Cg + L-arg groups were similar to that of the control group.

3.7. Effect of AE-ITU, L-NNA, NOC-18, or L-Arginine on the Release of TNF- $\alpha, I L-1 \beta$, and MCP-1. We measured the levels of TNF- $\alpha$ (Figure 7(a)), IL-1 $\beta$ (Figure 7(b)), and MCP1 (Figure $7(\mathrm{c})$ ) in the pleural exudates. The Cg group had a higher level of TNF- $\alpha$ as compared to the control group $(P<.01)$. The $\mathrm{Cg}+\mathrm{AE}-\mathrm{ITU}$ and $\mathrm{Cg}+\mathrm{L}-\mathrm{NNA}$ groups had the highest levels of TNF- $\alpha$ in comparison to the Cg group (both $P<.05$ ) and the control group (both $P<.01$ ). The levels of TNF- $\alpha$ in the Cg + NOC-18 and Cg + L-arg groups were lower than that of the Cg group (both $P<.01$ ) but higher than that of the control group (both $P<.01$ ). The $\mathrm{Cg}(P<.01), \mathrm{Cg}+\mathrm{AE}-\mathrm{ITU}(P<.01)$ and $\mathrm{Cg}+\mathrm{L}-\mathrm{NNA}$ groups $(P<.01)$ had increased IL-1 $\beta$ levels as compared to the control group, while the Cg + NOC-18 $(P<.01)$ and $\mathrm{Cg}+\mathrm{L}$-arg groups $(P<.05)$ had reduced IL- $1 \beta$ levels as compared to the $\mathrm{Cg}$ group. However, in the $\mathrm{Cg}+\mathrm{L}$-arg group, the level of IL- $1 \beta$ was higher compared to the control group $(P<.05)$, while there was no difference between the IL- $1 \beta$ levels of the Cg + NOC-18 and control groups. Like the TNF$\alpha$ and IL- $1 \beta$ levels, the MCP- 1 levels in the $\mathrm{Cg}+\mathrm{AE}-\mathrm{ITU}$ and $\mathrm{Cg}+\mathrm{L}-\mathrm{NNA}$ groups were increased as compared to the $\mathrm{Cg}$ group (both $P<.05)$. The MCP-1 levels of the Cg + NOC18 and $\mathrm{Cg}+\mathrm{L}$-arg groups were significantly lower than that 


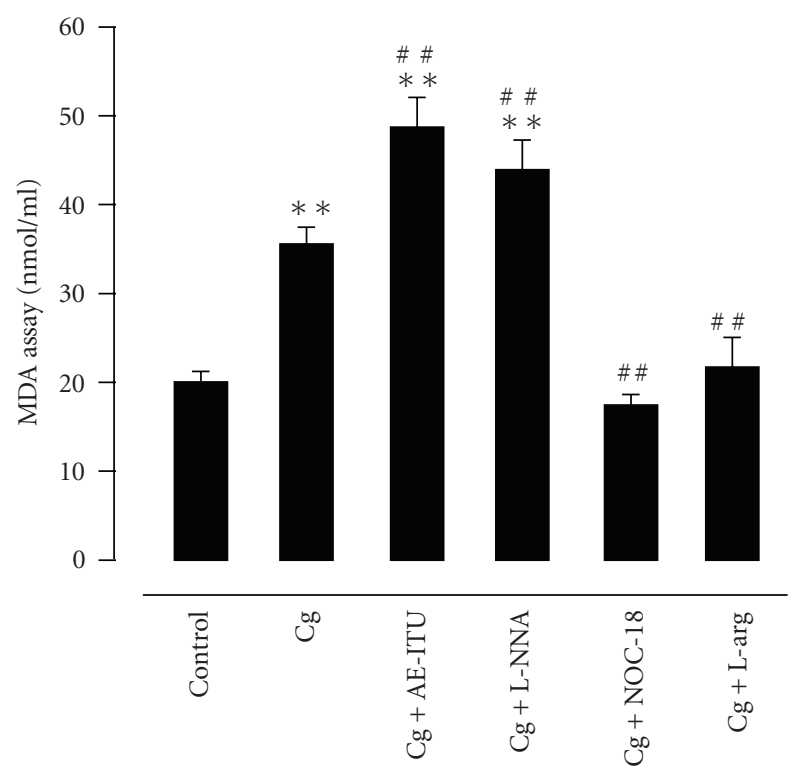

Figure 6: Effect of AE-ITU, L-NNA, NOC-18, and L-arginine on malondialdehyde (MDA) content in the pleural exudates 6 hours after Cg challenge. Data are expressed as mean \pm S.E.M. of 6 to 8 rats. ${ }^{* *} P<.01$ as compared to control group; ${ }^{\#} P<.01$ as compared to Cg group.

of the Cg group (both $P<.05$ ) and significantly higher than that of the control group (both $P<.01$ ).

3.8. Effect of AE-ITU, L-NNA, NOC-18 or L-Arginine on TAOS Activity in Pleural Exudates. The Cg group had a lower level of TAOS activity as compared to the control group $(P<$ .01) (Figure 8). The $\mathrm{Cg}+\mathrm{AE}-\mathrm{ITU}$ and $\mathrm{Cg}+\mathrm{L}-\mathrm{NNA}$ groups had the lowest level of TAOS activity in comparison to the $\mathrm{Cg}$ group (both $P<.01$ ) and the control group (both $P<.01$ ). In contrast, the TAOS activity levels in the Cg + NOC-18 and $\mathrm{Cg}+\mathrm{L}$-arg groups were increased in comparison to the $\mathrm{Cg}$ group (both $P<.01$ ) and similar to that of the control group.

\section{Discussion}

Nitric oxide is a signaling molecule responsible for diverse physiological and pathophysiological processes. Until now, the prevailing hypothesis about $\mathrm{NO}$ is that it contributes to toxicant-induced pleural inflammation and injury [30, 31]. The present study suggests a different role for $\mathrm{NO}$ in the rat pleural inflammatory response induced by $\mathrm{Cg}$. We found that the administration of an NO donor (NOC18) or NO substrate (L-arginine) reduced the migration of inflammatory cells and edema formation, lowered oxidative stress, and normalized antioxidant enzyme activities. The action of NO here was different from its actions elicited by other pleura and/or lung inflammatory stimuli such as lipopolysaccharide (LPS), des-Arg9-bradykinin, or substance $\mathrm{P}$ [32-34]. Although several studies have described NO as a mediator of the inflammatory response-for example, by stimulating production of inflammatory cytokines and peroxynitrite $\left(\mathrm{ONOO}^{-}\right)[4,5]$-beneficial effects of $\mathrm{NO}$ during inflammatory insult have also been reported [10-15, 25, 27].

We observed a reduction in the number of inflammatory cells within the pleural cavity in the $\mathrm{Cg}+\mathrm{NOC}-18$ and $\mathrm{Cg}+\mathrm{L}$-arg groups as compared to the $\mathrm{Cg}$ group. The specific action of $\mathrm{NO}$ on inflammatory cells is unknown, but we suggest that NOC-18 and L-arginine may reduce the expression of endothelial cell adhesion molecules and consequently reduce the inflammatory cell migration into the pleural space. Furthermore, NO was reported to be an important molecule for blocking the endothelium-leukocyte interaction $[35,36]$. Apoptosis of inflammatory cells during the inflammatory process by $\mathrm{Cg}$ injection through $\mathrm{NO}$ activation of death domains is another hypothesis to explain the reduced number of inflammatory cells within the pleural cavity in the $\mathrm{Cg}+\mathrm{NOC}-18$ and $\mathrm{Cg}+\mathrm{L}-$ arg groups, due to the involvement of $\mathrm{NO}$ in apoptosis $[36,37]$. By contrast, L-NNA, an inhibitor of cNOS and iNOS, or AE-ITU, a selective iNOS inhibitor, resulted in an increased level of leukocytes as compared to the $\mathrm{Cg}$ group. Therefore, although Cg itself increased nitrite/nitrate formation, decreasing the nitrite/nitrate formation with LNNA or AE-ITU actually exacerbated the inflammatory response in terms of leukocyte levels and exudate volume. The effects of the NOS inhibitors on leukocyte migration appear to be a consequence of the inhibition of the Larginine/NO pathway, because the enhancement of leukocyte migration was reversed by cotreatment with L-arginine and NOC-18. These data help to explain the positive effects of an NO donor or substrate in decreasing the inflammatory response by lowering cell recruitment into the inflammatory site. However, it is possible that the contribution of NO to the development of the inflammatory reaction depends on the intensity of tissue injury and integrity of the structures involved in the process. Future efforts also will undoubtedly focus on attempting to decipher the differences in the time course of pharmacological assays, doses, and the observation time intervals.

The fact that the $\mathrm{IC}_{50}$ of L-NNA for the inhibition of eNOS is around 10 times lower than that for iNOS inhibition [24] suggests that, at low doses, L-NNA is inhibiting predominantly the eNOS isoform. This, together with the demonstration that AE-ITU, a selective inhibitor of iNOS [23], enhanced the leukocyte migration, suggests that during the inflammatory process, NO, which modulates the leukocyte migration, is synthesized by either eNOS or iNOS. There is evidence in the literature that during the inflammatory process the expression of eNOS or its activity is enhanced [38] and iNOS is induced [39]. Additionally, other authors have demonstrated that NO downmodulates the leukocyte migration during the inflammatory process and that it is released by both NOS isoforms. Animals treated with selective iNOS inhibitors (aminoguanidine, 1400W, LNIL and AE-ITU) or a selective eNOS inhibitor (L-NIO) present enhanced leukocyte migration to inflammatory sites $[25,27,40,41]$. Furthermore, the NO donors, SIN-1, spermine-NO, sodium nitroprusside, and NOC-18, inhibit both the adhesion and leukocyte migration induced by 


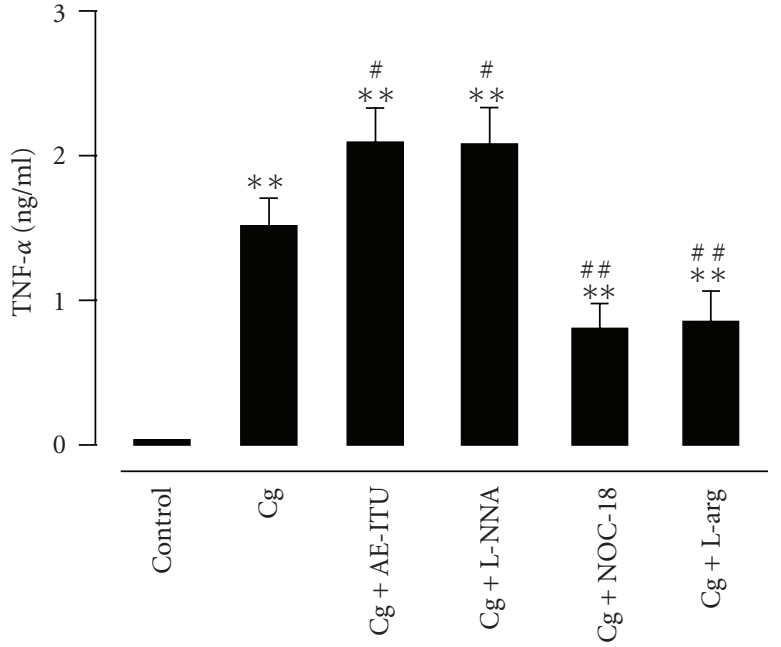

(a)

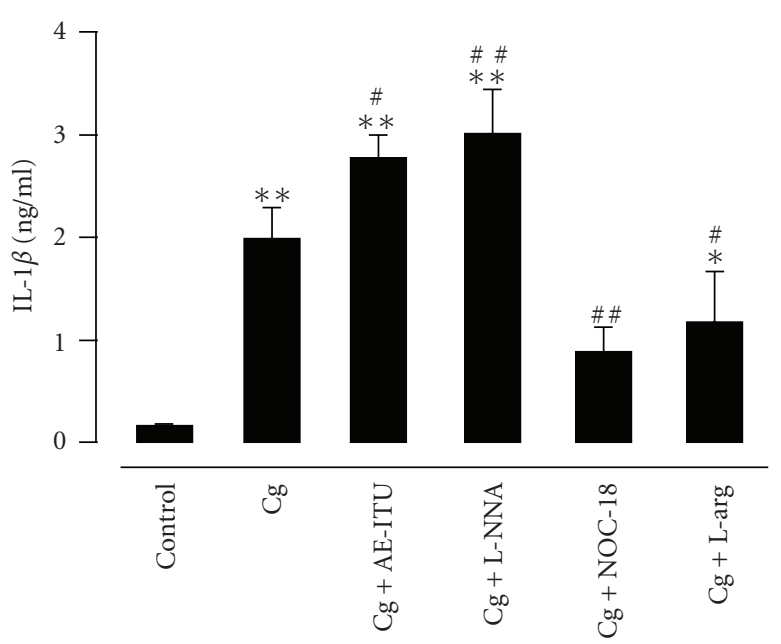

(b)

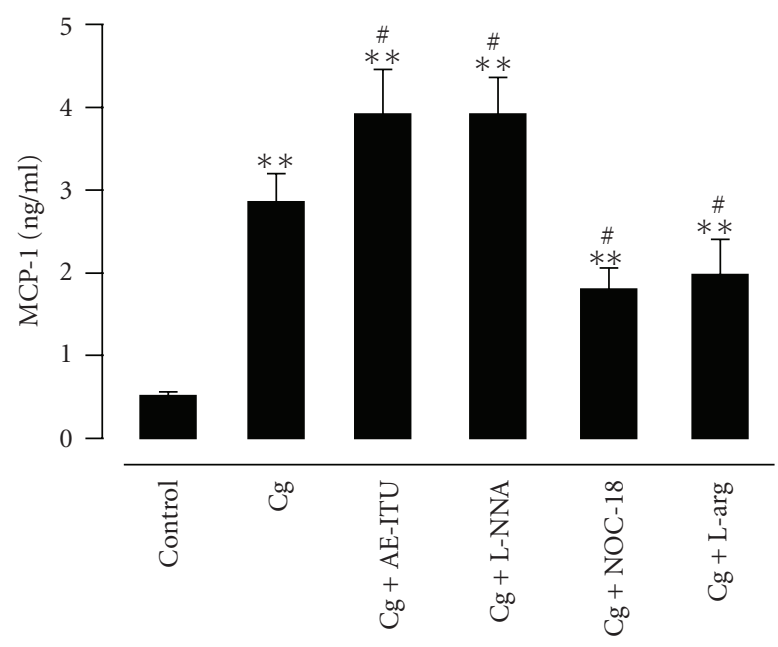

(c)

Figure 7: Effects of AE-ITU, L-NNA, NOC-18 and L-arginine on the release of cytokines. Tumor necrosis factor- $\alpha$ (TNF- $\alpha$ ) (a), interleukin$1 \beta$ (IL-1 $\beta$ ) (b) and monocyte chemoattractant protein-1 (MCP-1) (c) levels in the pleural exudates 6 hours after Cg challenge. Data are expressed as mean \pm S.E.M. from 6 to 8 rats. ${ }^{*} P<.05$, ${ }^{* *} P<.01$ as compared to control group; ${ }^{\#} P<.05$, ${ }^{\# \#} P<.01$ as compared to Cg group.

LPS, IL-1, Cg, or ischemia/reperfusion [27, 42-45]. On the other hand, there are some studies that contradict these reports and our own findings. Animals treated with NOS inhibitors (L-NAME, L-NIL, L-NMMA, or aminoguanidine) or iNOS knockout mice present a reduction in the leukocyte migration induced by staphylococcal enterotoxin B (SEB), zymosan, SWC, or Cg [40, 46-48]. It has been suggested that these apparently conflicting data could be a consequence of vasoconstriction, leading to reduced local blood flow, due to the use of high doses and/or systemic administration of the drugs $[25,27]$. However, decreased blood flow in the microcirculation cannot completely explain the reduction in leukocyte migration induced by zymosan and $\mathrm{Cg}$ in iNOS knockout mice $[46,47]$, which do not experience changes in blood pressure after the inflammatory stimuli injection. We do not have an explanation for these differences; however, in our study, rats treated with L-NNA or AE-ITU and injected with $\mathrm{Cg}$ presented a massive leukocyte migration. It is important to point out that rats treated with the same dose of L-NNA did not present a significant increase in blood pressure [26].

Lipid peroxidation is an important marker of oxidative stress in pleuritis. Cg-induced pleurisy and lipid peroxidation (as analyzed by MDA) have been previously associated [28]. We found that MDA levels in Cg-injected animals were increased by NOS inhibitors. Treatment with NOC-18 or Larginine reduced the amount of MDA. This result is similar to that of Machová and coworkers [49], who showed that NO treatment inhibited lipid peroxidation in vitro and protected against cellular damage and cytotoxicity. NO has also been described as a scavenger of other far more toxic radicals and, therefore, an enhancer of defense mechanisms [50]. 


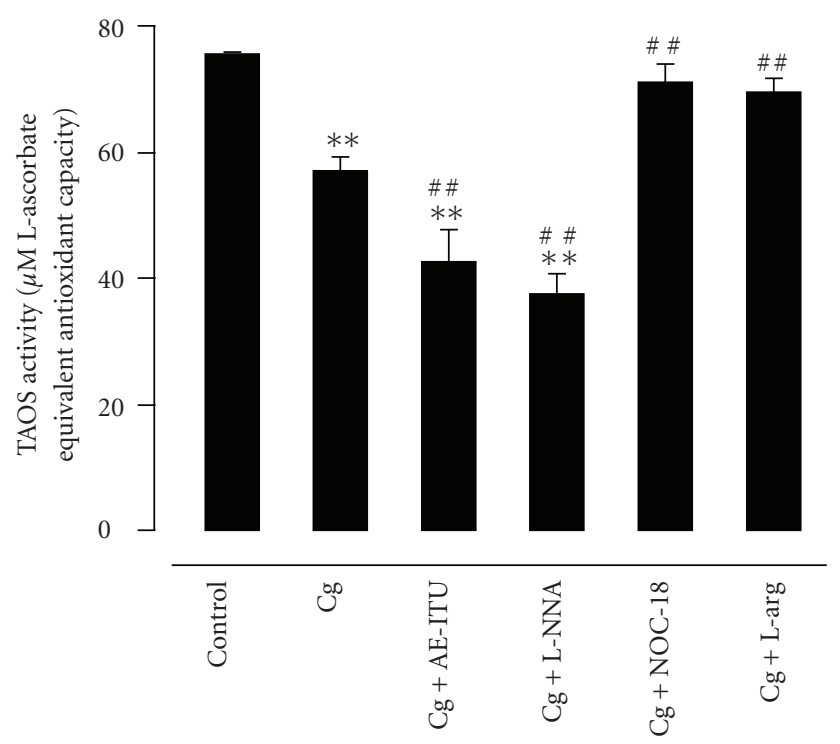

Figure 8: Effect of AE-ITU, L-NNA, NOC-18, and L-arginine on total antioxidant status (TAOS) activity in pleural exudates 6 hours after $\mathrm{Cg}$ challenge. Data are expressed as mean \pm S.E.M. from 6 to 8 rats. ${ }^{* *} P<.01$ as compared to the control group; ${ }^{\#} P<.01$ as compared to the $\mathrm{Cg}$ group.

Consequently, the increased levels of lipid peroxidation were observed only in the $\mathrm{Cg}+\mathrm{L}-\mathrm{NNA}$ and $\mathrm{Cg}+\mathrm{AE}-\mathrm{ITU}$ groups but not in the $\mathrm{Cg}+\mathrm{NOC}-18$ and $\mathrm{Cg}+\mathrm{L}-\arg$ groups.

There is substantial evidence that the pro-inflammatory cytokines TNF- $\alpha$ and IL- $1 \beta$ propagate the extension of a local or systemic inflammatory process $[51,52]$. We confirm here that the inflammatory process induced by $\mathrm{Cg}$ injection into the pleural cavity leads to substantial increases in the levels of TNF- $\alpha$ and IL- $1 \beta$ in the exudate. Interestingly, the inhibition of NO synthesis by L-NNA or AE-ITU further increased the levels of these two pro-inflammatory cytokines in the exudate, whereas NOC-18 or L-arginine did not cause a further increase. In support of this observation, others have shown that inhibition of NO synthesis by L-NAME in rats subjected to hepatic ischemia/reperfusion enhanced the expression of TNF- $\alpha$ and IL- $1 \beta$ mRNA in the ischemic lobes of liver and increased plasma levels of TNF- $\alpha$ and IL- $1 \beta$ [53]. Previous experiments have also shown that the NO donor SNAP dose dependently reduced the amounts of TNF- $\alpha$ and IL- $1 \beta$ produced by activated macrophages [54].

MCP-1 is a monocyte chemotactic factor that exerts potent and specific chemoattractant activity on both monocytes and neutrophils [21]. Monocytes and, to a lesser extent, granulocytes secrete MCP-1 in response to cytokines, viruses, bacterial endotoxins, and mitogens [55]. In vitro studies have shown that NO donors (NONOate compounds) inhibit the expression and production of MCP-1 in cytokine-activated human endothelial cells [56]. In addition, inhibition of endogenous NO synthesis by L-NNA increased endothelial MCP-1 mRNA expression and resulted in a marked increase in monocyte chemotactic activity [57], suggesting that NO modulates MCP-1 expression and activity in vitro. In agreement with these studies, we found that MCP-1 production in pleural exudates is downregulated by NOC-18 or L-arginine and upregulated by NOS inhibitors. Collectively, these results suggest that a compensatory increase in $\mathrm{NO}$ production at inflammatory sites critically regulates the severity of the inflammatory response by moderating the levels of such potently pro-inflammatory mediators as TNF- $\alpha$, IL- $1 \beta$, and MCP-1. Additionally, the lower levels of TNF- $\alpha$, IL- $1 \beta$, and MCP-1 in the $\mathrm{Cg}+$ NOC-18 and $\mathrm{Cg}+\mathrm{L}-\arg$ groups confirm the efficacy of treatment with an NO donor or substrate, leading us to hypothesize that NO is involved in blunting the inflammatory response.

We measured TAOS activity as an indirect indication of the formation of $\mathrm{O}_{2}{ }^{-}$and other oxidant species. This assay is based on the principle that oxidants formed during inflammation react with antioxidants such as glutathione, ascorbic acid, and $\alpha$-tocopherol [29] and reduce the antioxidant capacity of inflammatory exudates [58]. This index of $\mathrm{O}_{2}{ }^{-}$and other oxidant species was increased in the $\mathrm{Cg}+$ NOC-18 and Cg + L-arg groups in comparison with the $\mathrm{Cg}$ group, and these values were generally similar to those of the control group. Thus, the $\mathrm{Cg}+\mathrm{NOC}-18$ and $\mathrm{Cg}+\mathrm{L}$-arg groups appeared to downregulate $\mathrm{O}_{2}{ }^{-}$generation to some degree. In contrast, the TAOS activities of both the $\mathrm{Cg}+\mathrm{L}-$ NNA and $\mathrm{Cg}+\mathrm{AE}-\mathrm{ITU}$ groups were lower than those of the $\mathrm{Cg}$ and control groups, suggesting that $\mathrm{O}_{2}{ }^{-}$generation was enhanced in the absence of $\mathrm{NO} \mathrm{O}_{2}{ }^{-}$is produced by polymorphonuclear leukocytes and macrophages from the enzyme activity of NADPH oxidase and xanthine oxidase at inflammatory sites. Both enzyme systems contain a heme prosthetic group with which $\mathrm{NO}$ can react to inhibit $\mathrm{O}_{2}{ }^{-}$ release [59]. Therefore, inhibiting NO removes the brakes on $\mathrm{O}_{2}{ }^{-}$production. In support of this notion, others have shown that $\mathrm{NO}$ generation reduces $\mathrm{O}_{2}{ }^{-}$levels, while its inhibition increases $\mathrm{O}_{2}{ }^{-}$production both in vitro and in vivo $[60,61]$. As $\mathrm{O}_{2}{ }^{-}$has been associated with tissue damage and loss of function during inflammatory episodes [62], it is conceivable that one of the contributors to an enhanced inflammatory response, consequent to NOS inhibition, is $\mathrm{O}_{2}{ }^{-}$generation. Indeed, elevated levels of $\mathrm{O}_{2}{ }^{-}$increase TNF- $\alpha$ release from macrophages [63] and neutrophils and neutrophil activation through a Toll-like receptor 4dependent mechanism [64]. Increased levels of $\mathrm{O}_{2}^{-}$also activate NF- $\kappa \mathrm{B}[65]$, which may account for the increased production of IL- $1 \beta$. Although no direct effects of $\mathrm{O}_{2}{ }^{-}$on the upregulation of IL- $1 \beta$ have been demonstrated, an $\mathrm{O}_{2}{ }^{-}$ dismutase mimetic, M40403, significantly reduced NF- $\kappa \mathrm{B}$ DNA binding [66] and IL- $1 \beta$ production in inflamed lungs [67]. Moreover, in endothelial cells, adenovirus-mediated expression of $\mathrm{O}_{2}{ }^{-}$dismutase suppressed TNF- $\alpha$-induced MCP-1 mRNA expression and MCP-1 protein secretion [68]. Therefore, a disturbance in the balance between NO and $\mathrm{O}_{2}{ }^{-}$production may lead to an increase in proinflammatory mediators and provide a possible mechanism for the exacerbation of inflammation observed in the present study.

In summary, we showed that NO supplementation by NOC-18 or L-arginine reduced Cg-induced pleurisy and oxidative stress and regulated TNF- $\alpha$, IL1- $\beta$, MCP- 1 , and $\mathrm{O}_{2}{ }^{-}$levels at the inflammatory site. The NOS inhibitors 
exacerbated the inflammatory status in the pleural cavity of Cg-injected rats, contributed to oxidative stress, and induced a major imbalance between oxidants and antioxidants by maintaining high $\mathrm{O}_{2}^{-}$levels, favoring the oxidant side. Supplementation with NO may be a promising treatment for inflammatory diseases that involve oxidative stress, but further investigations are needed to confirm this hypothesis.

\section{References}

[1] A. Ueno and S. Oh-ishi, "Critical roles for bradykinin and prostanoids in acute inflammatory reactions: a search using experimental animal models," Current Drug Targets: Inflammation and Allergy, vol. 1, no. 4, pp. 363-376, 2002.

[2] S. Moncada, R. M. J. Palmer, and E. A. Higgs, "Nitric oxide: physiology, pathophysiology, and pharmacology," Pharmacological Reviews, vol. 43, no. 2, pp. 109-142, 1991.

[3] R. M. Clancy, A. R. Amin, and S. B. Abramson, "The role of nitric oxide in inflammation and immunity," Arthritis and Rheumatism, vol. 41, no. 7, pp. 1141-1151, 1998.

[4] H. Yaren, H. Mollaoglu, B. Kurt, et al., "Lung toxicity of nitrogen mustard may be mediated by nitric oxide and peroxynitrite in rats," Research in Veterinary Science, vol. 83, no. 1, pp. 116-122, 2007.

[5] J.-L. Zhou, G.-H. Jin, Y.-L. Yi, J.-L. Zhang, and X.-L. Huang, "Role of nitric oxide and peroxynitrite anion in lung injury induced by intestinal ischemia-reperfusion in rats," World Journal of Gastroenterology, vol. 9, no. 6, pp. 1318-1322, 2003.

[6] N. McCartney-Francis, J. B. Allen, D. E. Mizel, et al., "Suppression of arthritis by an inhibitor of nitric oxide synthase," Journal of Experimental Medicine, vol. 178, no. 2, pp. 749-754, 1993.

[7] M. Stefanovic-Racic, K. Meyers, C. Meschter, J. W. Coffey, R. A. Hoffman, and C. H. Evans, "N-monomethyl arginine, an inhibitor of nitric oxide synthase, suppresses the development of adjuvant arthritis in rats," Arthritis and Rheumatism, vol. 37, no. 7, pp. 1062-1069, 1994.

[8] C. R. White, T. A. Brock, L.-Y. Chang, et al., "Superoxide and peroxynitrite in atherosclerosis," Proceedings of the National Academy of Sciences of the United States of America, vol. 91, no. 3, pp. 1044-1048, 1994.

[9] N. W. Kooy, J. A. Royall, Y. Z. Ye, D. R. Kelly, and J. S. Beckman, "Evidence for in vivo peroxynitrite production in human acute lung injury," American Journal of Respiratory and Critical Care Medicine, vol. 151, no. 4, pp. 1250-1254, 1995.

[10] D. A. Wink, I. Hanbauer, M. C. Krishna, W. DeGraff, J. Gamson, and J. B. Mitchell, "Nitric oxide protects against cellular damage and cytotoxicity from reactive oxygen species," Proceedings of the National Academy of Sciences of the United States of America, vol. 90, no. 21, pp. 9813-9817, 1993.

[11] A. P. Bautista and J. J. Spitzer, "Inhibition of nitric oxide formation in vivo enhances superoxide release by the perfused liver," American Journal of Physiology, vol. 266, no. 5, pp. G783-G788, 1994.

[12] D. Payne and P. Kubes, "Nitric oxide donors reduce the rise in reperfusion-induced intestinal mucosal permeability," American Journal of Physiology, vol. 265, no. 1, pp. G189G195, 1993.

[13] P. J. Shultz and L. Raij, "Endogenously synthesized nitric oxide prevents endotoxin-induced glomerular thrombosis," Journal of Clinical Investigation, vol. 90, no. 5, pp. 1718-1725, 1992.
[14] S. S. Valença, W. A. Pimenta, C. R. Rueff-Barroso, et al., "Involvement of nitric oxide in acute lung inflammation induced by cigarette smoke in the mouse," Nitric Oxide, vol. 20, no. 3, pp. 175-181, 2009.

[15] M. B. West, G. Rokosh, D. Obal, et al., "Cardiac myocytespecific expression of inducible nitric oxide synthase protects against ischemia/reperfusion injury by preventing mitochondrial permeability transition," Circulation, vol. 118, no. 19, pp. 1970-1978, 2008.

[16] A. R. Moore, "Pleural models of inflammation: immune and nonimmune," Methods in Molecular Biology, vol. 225, pp. 123$128,2003$.

[17] A. Tomlinson, I. Appleton, A. R. Moore, et al., "Cyclooxygenase and nitric oxide synthase isoforms in rat carrageenin-induced pleurisy," British Journal of Pharmacology, vol. 113, no. 3, pp. 693-698, 1994.

[18] D. Willis, A. R. Moore, R. Frederick, and D. A. Willoughby, "Heme oxygenase: a novel target for the modulation of the inflammatory response," Nature Medicine, vol. 2, no. 1, pp. 8790, 1996.

[19] M. P. Keane and R. M. Strieter, "Chemokine signaling in inflammation," Critical Care Medicine, vol. 28, no. 4, supplement, pp. N13-N26, 2000.

[20] P. Puneet, S. Moochhala, and M. Bhatia, "Chemokines in acute respiratory distress syndrome," American Journal of Physiology, vol. 288, no. 1, pp. L3-L15, 2005.

[21] K. Christopherson II and R. Hromas, "Chemokine regulation of normal and pathologic immune responses," Stem Cells, vol. 19, no. 5, pp. 388-396, 2001.

[22] M. Feelisch and J. S. Stamler, "Donors of nitrogen oxides," in Methods in Nitric Oxide Research, M. Feelisch and J. S. Stamler, Eds., pp. 71-115, John Wiley \& Sons, New York, NY, USA, 1996.

[23] G. J. Southan, C. Szabó, and C. Thiemermann, "Isothioureas: potent inhibitors of nitric oxide synthases with variable isoform selectivity," British Journal of Pharmacology, vol. 114, no. 2, pp. 510-516, 1995.

[24] W. K. Alderton, C. E. Cooper, and R. G. Knowles, "Nitric oxide synthases: structure, function and inhibition," Biochemical Journal, vol. 357, no. 3, pp. 593-615, 2001.

[25] M. J. Paul-Clark, D. W. Gilroy, D. Willis, D. A. Willoughby, and A. Tomlinson, "Nitric oxide synthase inhibitors have opposite effects on acute inflammation depending on their route of administration," Journal of Immunology, vol. 166, no. 2, pp. 1169-1177, 2001.

[26] Y.-X. Wang and C. C. Y. Pang, "Possible dependence of pressor and heart rate effects of $\mathrm{N}(\mathrm{G})$-nitro-L-arginine on autonomic nerve activity," British Journal of Pharmacology, vol. 103, no. 4, pp. 2004-2008, 1991.

[27] A. Ialenti, A. Ianaro, P. Maffia, L. Sautebin, and M. Di Rosa, "Nitric oxide inhibits leucocyte migration in carrageenininduced rat pleurisy," Inflammation Research, vol. 49, no. 8, pp. 411-417, 2000.

[28] H. H. Draper, E. J. Squires, H. Mahmoodi, J. Wu, S. Agarwal, and M. Hadley, "A comparative evaluation of thiobarbituric acid methods for the determination of malondialdehyde in biological materials," Free Radical Biology and Medicine, vol. 15, no. 4, pp. 353-363, 1993.

[29] D. W. Laight, P. T. Gunnarsson, A. V. Kaw, E. E. Änggård, and M. J. Carrier, "Physiological microassay of plasma total antioxidant status in a model of endothelial dysfunction in the rat following experimental oxidant stress in vivo," Environmental Toxicology and Pharmacology, vol. 7, no. 1, pp. 27-31, 1999. 
[30] O. Menezes-De-Lima Jr., E. Werneck-Barroso, R. S. Cordeiro, and M. G. Henriques, "Effects of inhibitors of inflammatory mediators and cytokines on eosinophil and neutrophil accumulation induced by Mycobacterium bovis bacillus CalmetteGuerin in mouse pleurisy," Journal of Leukocyte Biology, vol. 62, no. 6, pp. 778-785, 1997.

[31] A. Lunardelli, C. E. Leite, M. G. Pires, and J. R. De Oliveira, "Extract of the bristles of Dirphia sp. increases nitric oxide in a rat pleurisy model," Inflammation Research, vol. 55, no. 4, pp. 129-135, 2006.

[32] M. M. Rafi, P. N. Yadav, and M. Reyes, "Lycopene inhibits LPSinduced proinflammatory mediator inducible nitric oxide synthase in mouse macrophage cells," Journal of Food Science, vol. 72, no. 1, pp. S069-S074, 2007.

[33] R. M. Vianna and J. B. Calixto, "Characterization of the receptor and the mechanisms underlying the inflammatory response induced by des-Arg9-BK in mouse pleurisy," British Journal of Pharmacology, vol. 123, no. 2, pp. 281-291, 1998.

[34] T. S. Fröde-Saleh, J. B. Calixto, and Y. S. Medeiros, "Analysis of the inflammatory response induced by substance $\mathrm{P}$ in the mouse pleural cavity," Peptides, vol. 20, no. 2, pp. 259-265, 1999.

[35] C. Bouzin, A. Brouet, J. De Vriese, J. DeWever, and O. Feron, "Effects of vascular endothelial growth factor on the lymphocyte-endothelium interactions: identification of caveolin-1 and nitric oxide as control points of endothelial cell anergy," Journal of Immunology, vol. 178, no. 3, pp. 1505-1511, 2007.

[36] D. Dal Secco, J. A. Paron, S. H. de Oliveira, S. H. Ferreira, J. S. Silva, and F. Q. Cunha, "Neutrophil migration in inflammation: nitric oxide inhibits rolling, adhesion and induces apoptosis," Nitric Oxide, vol. 9, no. 3, pp. 153-164, 2003.

[37] P. Chanvorachote, U. Nimmannit, L. Wang, et al., "Nitric oxide negatively regulates Fas CD95-induced apoptosis through inhibition of ubiquitin-proteasome-mediated degradation of FLICE inhibitory protein," Journal of Biological Chemistry, vol. 280, no. 51, pp. 42044-42050, 2005.

[38] G. Cirino, S. Fiorucci, and W. C. Sessa, "Endothelial nitric oxide synthase: the Cinderella of inflammation?" Trends in Pharmacological Sciences, vol. 24, no. 2, pp. 91-95, 2003.

[39] D. G. Binion, S. Fu, K. S. Ramanujam, et al., "iNOS expression in human intestinal microvascular endothelial cells inhibits leukocyte adhesion," American Journal of Physiology, vol. 275, no. 3, pp. G592-G603, 1998.

[40] N. L. McCartney-Francis, X.-Y. Song, D. E. Mizel, and S. M. Wahl, "Selective inhibition of inducible nitric oxide synthase exacerbates erosive joint disease," Journal of Immunology, vol. 166, no. 4, pp. 2734-2740, 2001.

[41] B. M. Tavares-Murta, J. S. Machado, S. H. Ferreira, and F. Q. Cunha, "Nitric oxide mediates the inhibition of neutrophil migration induced by systemic administration of LPS," Inflammation, vol. 25, no. 4, pp. 247-253, 2001.

[42] F. Lopez-Neblina, L. H. Toledo-Pereyra, R. Mirmiran, and A. J. Paez-Rollys, "Time dependence of Na-nitroprusside administration in the prevention of neutrophil infiltration in the rat ischemic kidney," Transplantation, vol. 61, no. 2, pp. 179-183, 1996.

[43] D. M. Guidot, B. M. Hybertson, R. P. Kitlowski, and J. E. Repine, "Inhaled NO prevents IL-1-induced neutrophil accumulation and associated acute edema in isolated rat lungs," American Journal of Physiology, vol. 271, no. 2, pp. L225-L229, 1996.
[44] K. Lelamali, W. Wang, P. Gengaro, C. Edelstein, and R. W. Schrier, "Effects of nitric oxide and peroxynitrite on endotoxin-induced leukocyte adhesion to endothelium," Journal of Cellular Physiology, vol. 188, no. 3, pp. 337-342, 2001.

[45] P. Kubes, I. Kurose, and D. N. Granger, "NO donors prevent integrin-induced leukocyte adhesion but not P-selectindependent rolling in postischemic venules," American Journal of Physiology, vol. 267, no. 3, pp. H931-H937, 1994.

[46] M. N. Ajuebor, L. Virág, R. J. Flower, M. Perretti, and C. Szabó, "Role of inducible nitric oxide synthase in the regulation of neutrophil migration in zymosan-induced inflammation," Immunology, vol. 95, no. 4, pp. 625-630, 1998.

[47] S. Cuzzocrea, E. Mazzon, G. Calabro, et al., "Inducible nitric oxide synthase-knockout mice exhibit resistance to pleurisy and lung injury caused by carrageenan," American Journal of Respiratory and Critical Care Medicine, vol. 162, no. 5, pp. 1859-1866, 2000.

[48] C. F. Franco-Penteado, I. DeSouza, S. A. Teixeira, G. RibeiroDaSilva, G. De Nucci, and E. Antunes, "Involvement of nitric oxide on the peritoneal neutrophil influx induced by staphylococcal enterotoxin B in mouse," Toxicon, vol. 39, no. 9, pp. 1383-1386, 2001.

[49] J. Machová, M. Stefek, M. Kukan, et al., "Involvement of L-arginine-nitric oxide system in the response of isolated trachea to reactive oxygen species," Methods and Findings in Experimental and Clinical Pharmacology, vol. 25, no. 4, pp. 287-296, 2003.

[50] G. A. Blaise, D. Gauvin, M. Gangal, and S. Authier, "Nitric oxide, cell signaling and cell death," Toxicology, vol. 208, no. 2, pp. 177-192, 2005.

[51] I. Utsunomiya, S. Nagai, and S. Oh-ishi, "Sequential appearance of IL-1 and IL-6 activities in rat carrageenin-induced pleurisy," Journal of Immunology, vol. 147, no. 6, pp. 18031809, 1991.

[52] I. Utsunomiya, M. Ito, and S. Oh-ishi, "Generation of inflammatory cytokines in zymosan-induced pleurisy in rats: TNF induces IL-6 and cytokine-induced neutrophil chemoattractant (CINC) in vivo," Cytokine, vol. 10, no. 12, pp. 956963, 1998.

[53] P. Liu, B. Xu, E. Spokas, P.-S. Lai, and P. Y.-K. Wong, "Role of endogenous nitric oxide in TNF- $\alpha$ and IL- $1 \alpha$ generation in hepatic ischemia-reperfusion," Shock, vol. 13, no. 3, pp. 217223, 2000.

[54] D. R. Meldrum, B. D. Shames, X. Meng, et al., "Nitric oxide downregulates lung macrophage inflammatory cytokine production," Annals of Thoracic Surgery, vol. 66, no. 2, pp. 313-317, 1998.

[55] A. Wuyts, P. Proost, W. Put, J.-P. Lenaerts, L. Paemen, and J. van Damme, "Leukocyte recruitment by monocyte chemotactic proteins (MCPs) secreted by human phagocytes," Journal of Immunological Methods, vol. 174, no. 1-2, pp. 237247, 1994.

[56] A. Desai, M. J. Miller, X. Huang, and J. S. Warren, "Nitric oxide modulates MCP-1 expression in endothelial cells: implications for the pathogenesis of pulmonary granulomatous vasculitis," Inflammation, vol. 27, no. 4, pp. 213-223, 2003.

[57] A. M. Zeiher, B. Fisslthaler, B. Schray-Utz, and R. Busse, "Nitric oxide modulates the expression of monocyte chemoattractant protein 1 in cultured human endothelial cells," Circulation Research, vol. 76, no. 6, pp. 980-986, 1995.

[58] A. Van der Vliet, D. Smith, C. A. O’Neill, et al., "Interactions of peroxynitrite with human plasma and its constituents: oxidative damage and antioxidant depletion," Biochemical Journal, vol. 303, no. 1, pp. 295-301, 1994. 
[59] M. Fukahori, K. Ichimori, H. Ishida, H. Nakagawa, and H. Okino, "Nitric oxide reversibly suppresses xanthine oxidase activity," Free Radical Research, vol. 21, no. 4, pp. 203-212, 1994.

[60] J. Gaboury, R. C. Woodman, D. N. Granger, P. Reinhardt, and P. Kubes, "Nitric oxide prevents leukocyte adherence: role of superoxide," American Journal of Physiology, vol. 265, no. 3, pp. H862-H867, 1993.

[61] S. Selemidis, G. J. Dusting, H. Peshavariya, B. K. KempHarper, and G. R. Drummond, "Nitric oxide suppresses NADPH oxidase-dependent superoxide production by Snitrosylation in human endothelial cells," Cardiovascular Research, vol. 75, no. 2, pp. 349-358, 2007.

[62] V. L. Vega, M. Maldonado, L. Mardones, et al., "Inhibition of nitric oxide synthesis aggravates hepatic oxidative stress and enhances superoxide dismutase inactivation in rats subjected to tourniquet shock," Shock, vol. 9, no. 5, pp. 320-328, 1998.

[63] M. M. Ndengele, C. Muscoli, Z. Q. Wang, T. M. Doyle, G. M. Matuschak, and D. Salvemini, "Superoxide potentiates NF- $\kappa \mathrm{B}$ activation and modulates endotoxin-induced cytokine production in alveolar macrophages," Shock, vol. 23, no. 2, pp. 186-193, 2005.

[64] E. Lorne, J. W. Zmijewski, X. Zhao, et al., "Role of extracellular superoxide in neutrophil activation: interactions between xanthine oxidase and TLR4 induce proinflammatory cytokine production," American Journal of Physiology, vol. 294, no. 4, pp. C985-C993, 2008.

[65] C. K. Sen and L. Packer, "Antioxidant and redox regulation of gene transcription," FASEB Journal, vol. 10, no. 7, pp. 709-720, 1996.

[66] S. Cuzzocrea, B. Pisano, L. Dugo, A. Ianaro, M. Ndengele, and D. Salvemini, "Superoxide-related signaling cascade mediates nuclear factor- $\kappa \mathrm{B}$ activation in acute inflammation," Antioxidants and Redox Signaling, vol. 6, no. 4, pp. 699-704, 2004.

[67] D. Salvemini, E. Mazzon, L. Dugo, et al., "Pharmacological manipulation of the inflammatory cascade by the superoxide dismutase mimetic, M40403," British Journal of Pharmacology, vol. 132, no. 4, pp. 815-827, 2001.

[68] X.-L. Chen, Q. Zhang, R. Zhao, and R. M. Medford, "Superoxide, $\mathrm{H} 2 \mathrm{O} 2$, and iron are required for TNF- $\alpha$-induced MCP-1 gene expression in endothelial cells: role of Racl and NADPH oxidase," American Journal of Physiology, vol. 286, no. 3, pp. H1001-H1007, 2004. 


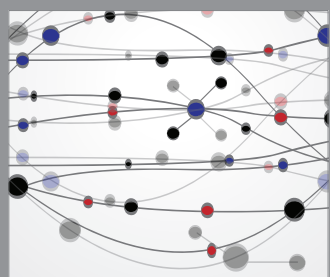

The Scientific World Journal
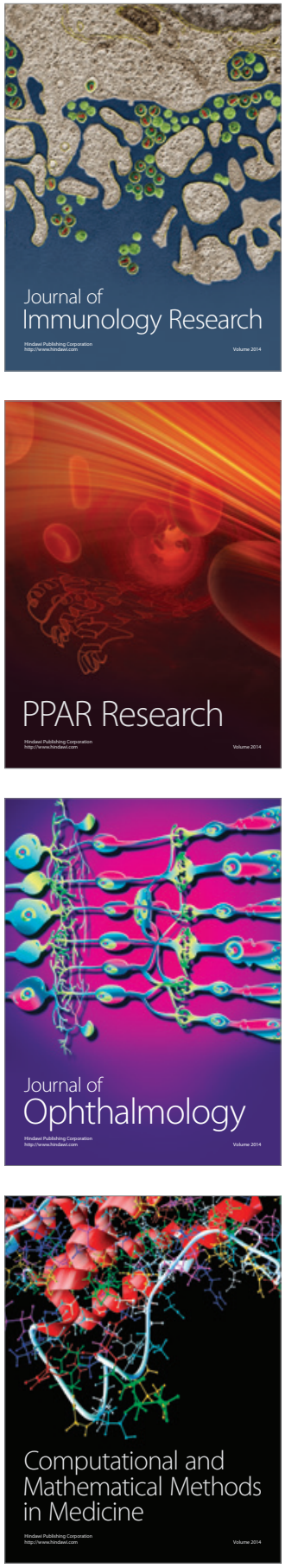

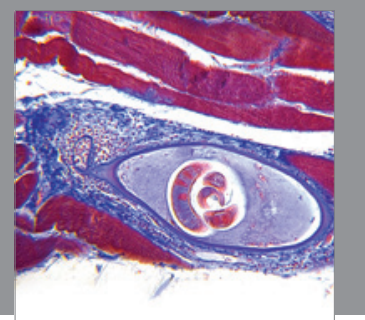

Gastroenterology

Research and Practice
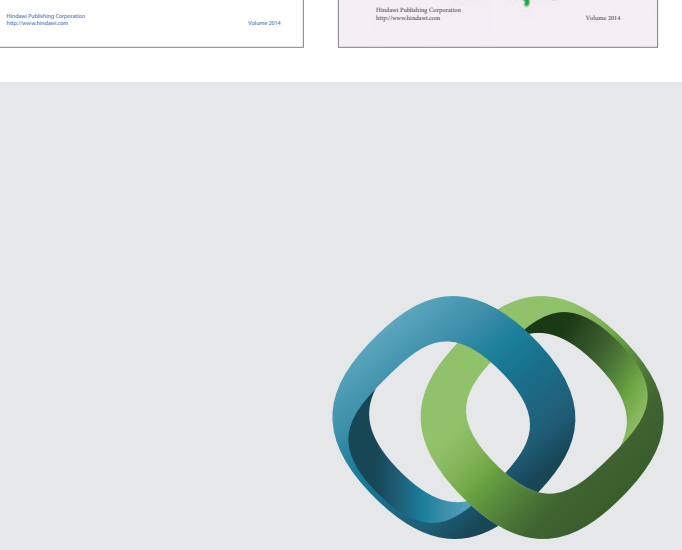

\section{Hindawi}

Submit your manuscripts at

http://www.hindawi.com
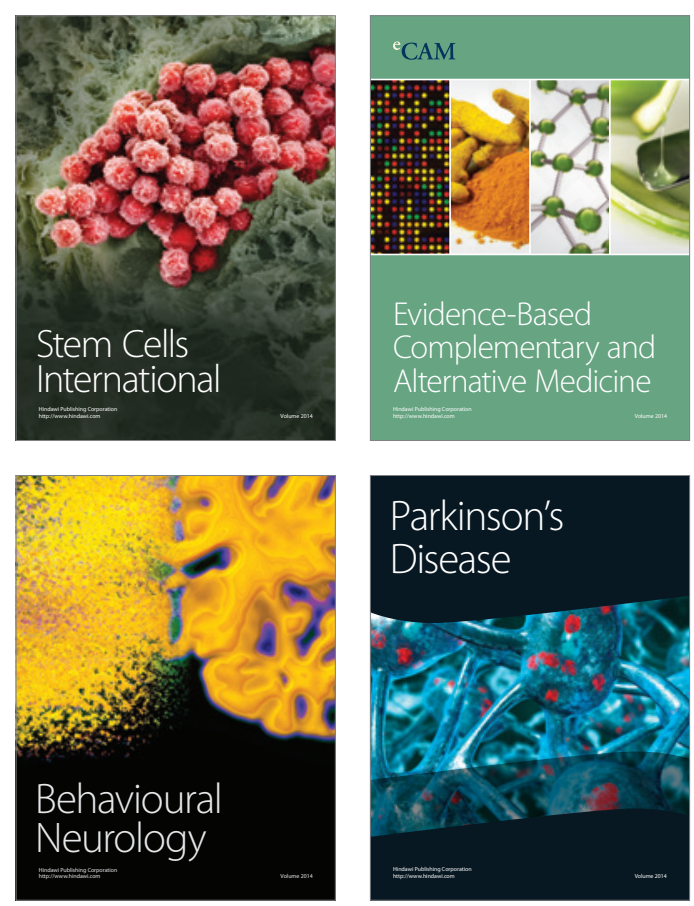

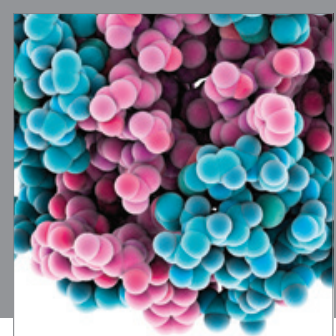

Journal of
Diabetes Research

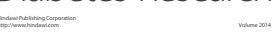

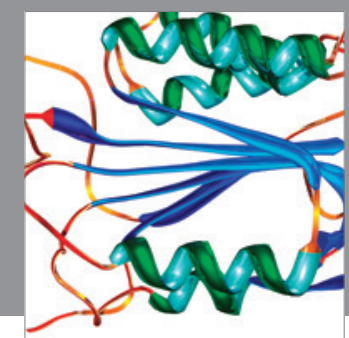

Disease Markers
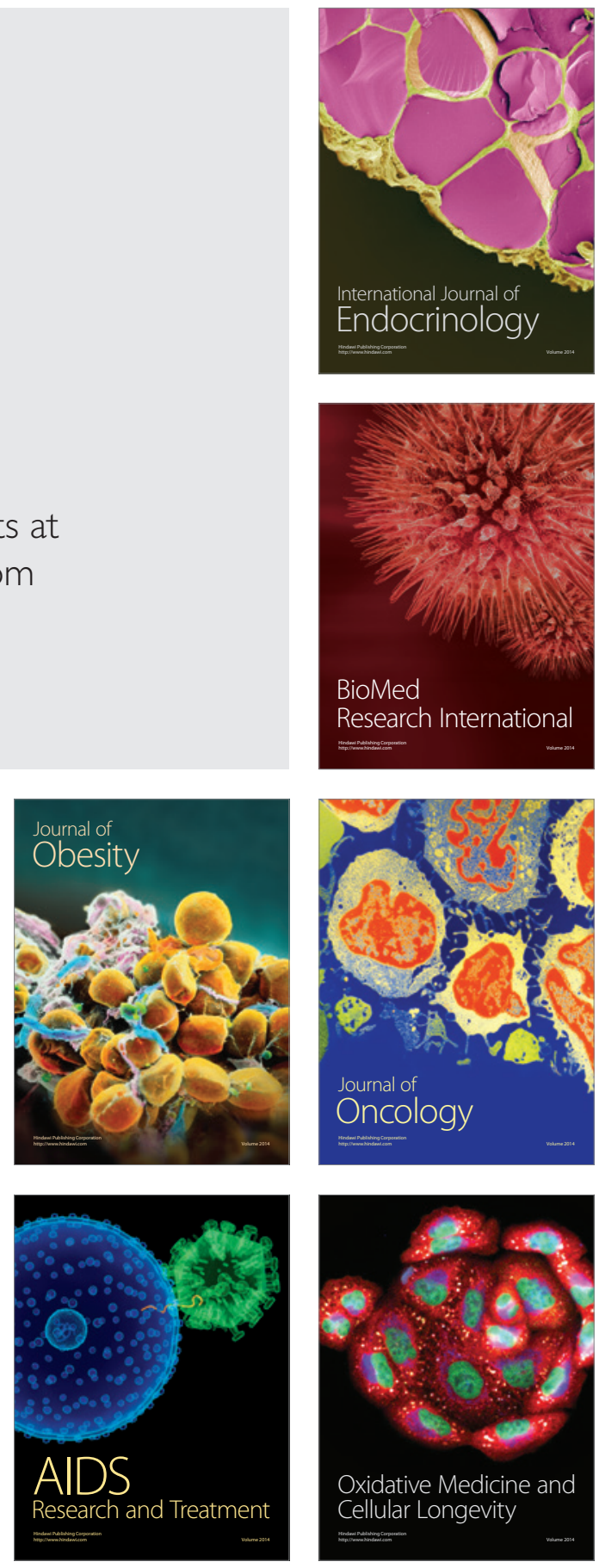